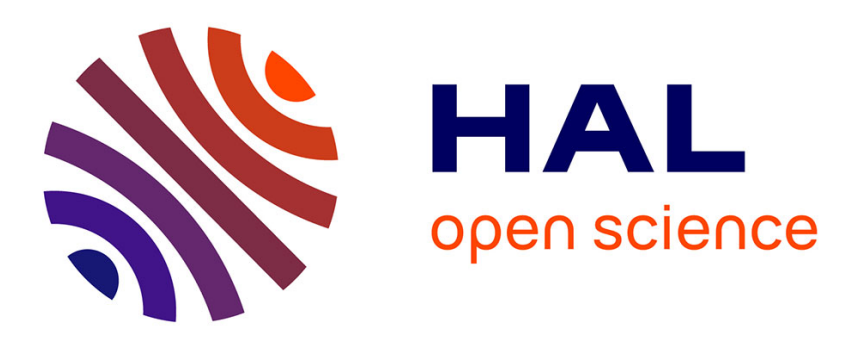

\title{
Multiband Pyramidal Antenna for Radio Navigation and Telemetry Systems
}

\author{
Sami Hebib, Hervé Aubert, Nelson Fonseca
}

\section{To cite this version:}

Sami Hebib, Hervé Aubert, Nelson Fonseca. Multiband Pyramidal Antenna for Radio Navigation and Telemetry Systems. 14th International Symposium on Antenna Technology and Applied Electromagnetics \& the American Electromagnetics Conference (ANTEM-AMEREM), 2010, Jul 2010, Ottawa, Canada. pp. 1-4, 10.1109/ANTEM.2010.5552559 . hal-00530348

\section{HAL Id: hal-00530348 \\ https://hal.science/hal-00530348}

Submitted on 28 Oct 2010

HAL is a multi-disciplinary open access archive for the deposit and dissemination of scientific research documents, whether they are published or not. The documents may come from teaching and research institutions in France or abroad, or from public or private research centers.
L'archive ouverte pluridisciplinaire HAL, est destinée au dépôt et à la diffusion de documents scientifiques de niveau recherche, publiés ou non, émanant des établissements d'enseignement et de recherche français ou étrangers, des laboratoires publics ou privés. 


\title{
Multiband Pyramidal Antenna for Radio Navigation and Telemetry Systems
}

\author{
Sami Hebib ${ }^{*(1,2)}$, Hervé Aubert ${ }^{(1,2)}$, Nelson J.G. Fonseca ${ }^{(1,2,3)}$ \\ (1) CNRS ; LAAS ; 7 avenue du colonel Roche, F-31077 Toulouse, France \\ sami.hebib@gmail.com,haubert@,laas.fr \\ (2) Université de Toulouse ; UPS, INSA, INP, ISAE ; LAAS ; F-31077 Toulouse, France \\ (3) European Space Agency, ESA/ESTEC, Keplerlaan 1, P.O. Box 299, 2200 \\ $A G$ Noordwijk $Z H$, the Netherlands \\ nelson.fonseca@esa.int
}

\begin{abstract}
A novel multi-band pyramidal antenna combining radio navigation and MicroSAT telemetry applications was recently introduced by the authors. This flexible antenna provides independent and easily adjustable operating frequency design. Furthermore, the radiation patterns of this pyramidal antenna are relatively similar at the different operating frequencies. One key element of this radiating structure is its cutoff waveguide placed underneath the antenna ground plane in order to improve input ports impedance matching while minimizing the antenna rear radiation level. This paper further describes the above-mentioned antenna and gives its latest improvements.
\end{abstract}

\section{INTRODUCTION}

There is a great need for multiband antennas in satellite systems, mainly driven by the objective of reducing the number of on-board antennas by integrating several applications on a single radiating element in order to save space in the platform. This is also applicable for radio navigation application alone, with new frequencies requiring wideband or multiband devices. Most of the proposed multiband antennas in the literature exhibit correlated operating frequencies. Consequently, the ratios between these operating frequencies are not independent and therefore not easy to monitor. Moreover, at different operating frequencies, the radiation patterns of these antennas are not much similar and are difficult to control.

The authors have recently introduced a new multi-band pyramidal antenna topology with independent and easily adjustable operating frequency ratios that combines radio navigation and telemetry applications [1], [2]. The proposed topology is also particularly flexible in terms of polarization as it depends only on the feeding network and not the radiating part. This antenna is composed of four identical radiating elements printed on the four sides of a square-base pyramid. The simple design of the radiating elements of this pyramidal antenna leads to a flexible concept, that is, the antenna can be easily adjusted in order to fulfill other frequency requirements. The multiband (or/and reconfigurable) behavior is simply obtained with trap-loads (or/and Radio-Frequency (RF) switches). The ground plane of the antenna has a central hole continued by a cylindrical cut- off waveguide: this original configuration improves the input ports impedance matching and allows to minimize, or even to monitor the antenna rear radiation [3]. Other ground plane configurations and loading structures can also be considered in order to reduce the size of the antenna while maintaining good RF performance. For instance, the use of truncated conical open-ended waveguide instead of the cylindrical waveguide allows a height reduction of $57 \%$ with comparable performance when compared to initial design [4].

According to the excitation law of the radiating elements, the antenna radiates either right-hand $(\mathrm{RH})$ or left-hand $(\mathrm{LH})$ circularly polarized (CP) electromagnetic fields. However, if two different polarizations are required, some difficulties in the design may appear at feeding network level. A recent solution to this drawback is to interleave two pyramidal antennas with a $45^{\circ}$ rotation to separate $\mathrm{RH}-\mathrm{CP}$ bands from LH-CP ones [5]. This original configuration does not affect the overall antenna size and $\mathrm{RH}-\mathrm{CP}$ band applications are naturally separated from $\mathrm{LH}-\mathrm{CP}$ ones making it easier to design the respective feeding networks. It also reduces the number of trap-loads (or/and RF switches) needed.

This paper provides an overview on these radio navigation related activities and describe the latest improvements on the pyramidal antenna design.

\section{MultiBAnd Pyramidal ANTENNA}

The originally proposed pyramidal antenna consists of 4 inclined radiating elements printed on a square-base pyramid [1], [2]. Trap-loads are used to achieve resonant multifrequency behavior. A designed and fabricated pyramidal triband antenna for GPS/GALILEO/MicroSat telemetry applications is shown in Fig 1 [1].

The use of simple monopoles as radiating elements offers easier design of the antenna. However, the authors have also investigated the potential of other radiating elements such as the Sierpinski monopoles [6]. This latter solution (see Fig.2) provides better bandwidth performance than that of a simple monopole pyramidal antenna (as a drawback, these triangular radiating elements require more trap-loads for multiband behavior than simple monopoles and occupy more space).

To improve input matching of the pyramidal antenna, the 
authors suggested to make a hole in the ground plane and continuing this hole by a cut-off cylindrical waveguide to keep reasonable rear radiation level [1]-[3]. This waveguide is designed such that no modes are propagating inside of it at the operating frequencies of the antenna. For the previous described triband antenna, Fig. 3 gives the variation of both the maximum directivity of rear radiation at the highest frequency and the minimum $S_{11}$ at the lowest frequency versus the length of the circular waveguide. As it can be seen, varying the length of the cut-off open-ended waveguide allows achieving a good tradeoff between rear radiation and impedance matching at feeding ports.

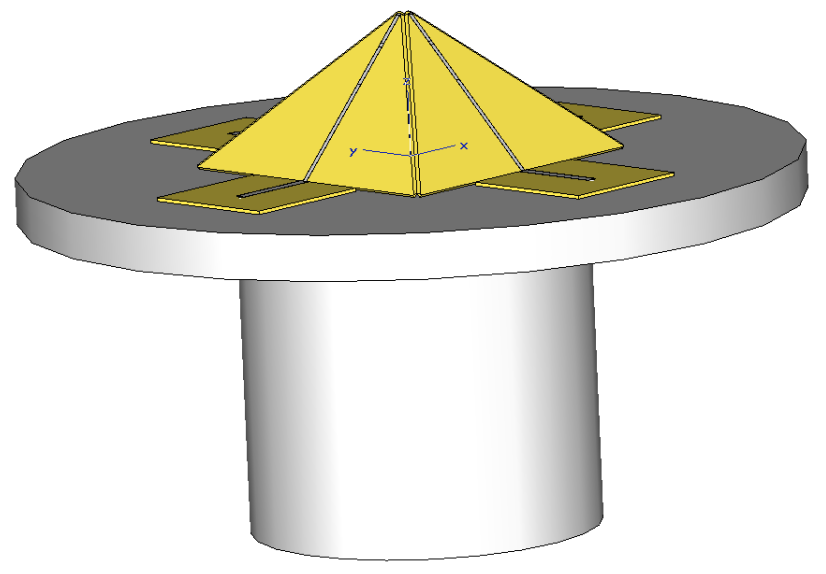

(a)

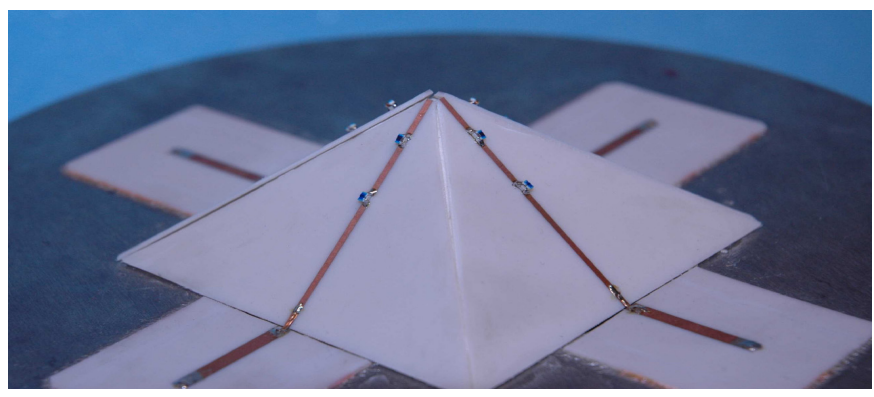

(b)

Fig. 1: Pyramidal multiband antenna with cut-off open-ended waveguide [1] (a) The simulation model; (b) Zoom on the fabricated pyramidal structure.

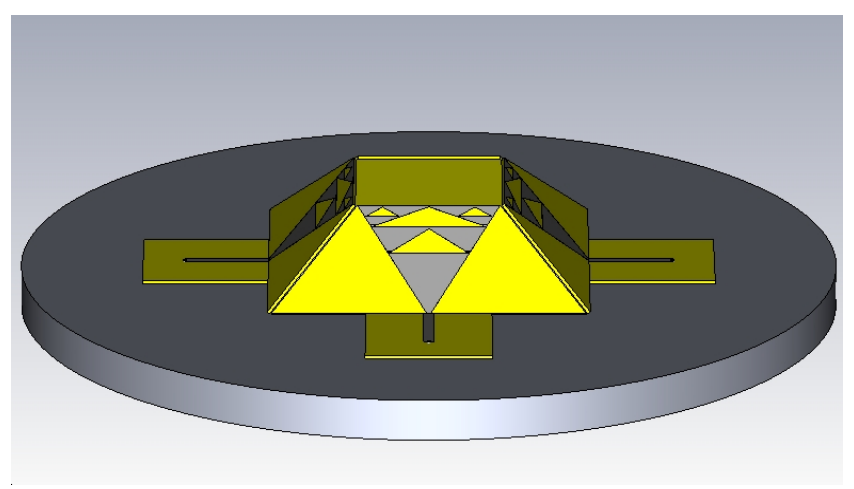

Fig.2: Sierpinski version of the pyramidal multiband antenna [6]

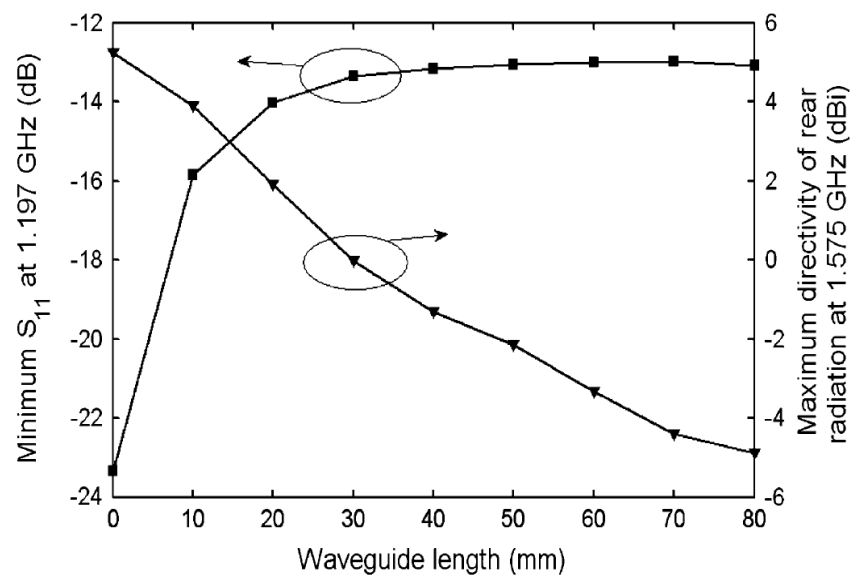

Fig. 3: The minimum $\mathrm{S}_{11}$ and the maximum rear radiation directivity versus the length of the cut-off and open-ended metallic waveguide [1]

The radiating elements arrangement is particularly interesting as the polarization depends only on the feeding network: feeding all the elements with same amplitude and a phase progression of + or $-90^{\circ}$ will produce a right or left hand circular polarization, while feeding only two opposite elements with same amplitude and $180^{\circ}$ phase shift enables linear polarization.

The simulated and measured $\mathrm{S}_{11}$ of the GPS/GALILEO/MicroSat telemetry triband antenna are depicted in Fig. 4. The Right Handed (RH-) and Left Handed (LH-) Circular Polarization (CP) directivity patterns are given only for the first operating frequency and shown in Fig 5.

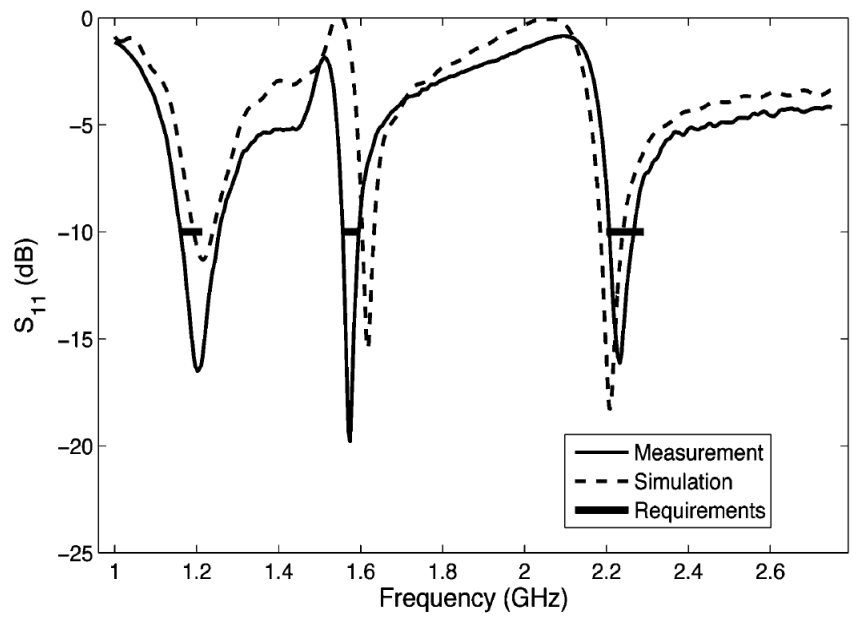

Fig. 4: $\mathrm{S}_{11}$ of the pyramidal GPS/GALILEO/MicroSat triband antenna [1].

As shown in Fig. 5, the radiation patterns of the antenna are quasi-hemispheric. Such radiation patterns are appropriate for satellite navigation reception antennas, thus allowing a maximum signal reception from the satellites in sight. 


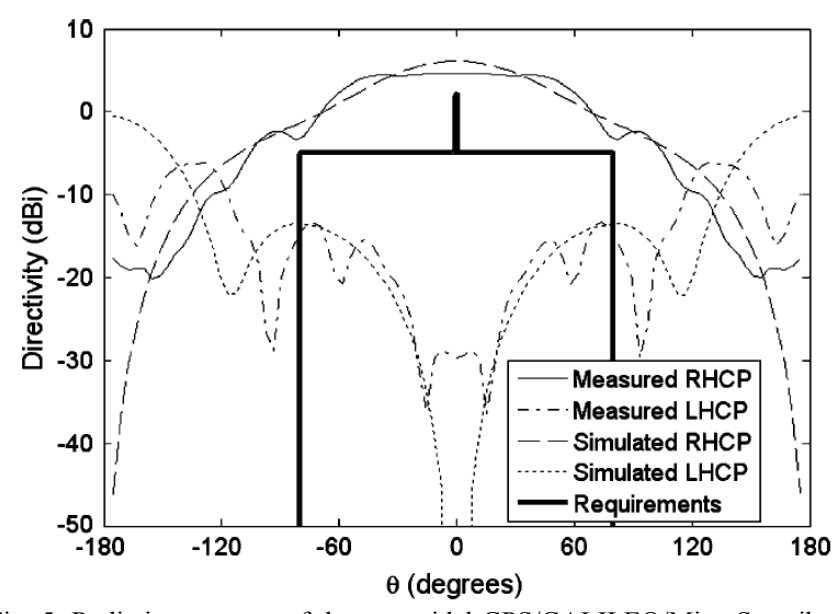

Fig. 5: Radiation patterns of the pyramidal GPS/GALILEO/MicroSat triband antenna at $1.2 \mathrm{GHz}[1]$.

Finally, in radio navigation applications, a design difficulty can arise when two successive frequency bands are too close for being considered as different bands but are also too distant to be easily matched on one single band of a multi-band antenna. A solution is then a multiband antenna with one or more bands being switchable. An example of a switchable dual-band pyramidal antenna for Aeronautical Radio Navigation Services (ARNS) and Radio Navigation Satellite Services (RNSS) is reported in [7].

\section{IMPACT OF THE GROUND PLANE AND ITS LOADING STRUCTURE}

In this part, some modifications on the ground plane and the loading structure of the initial concept are proposed. The main aim of these investigations was to reduce the overall height of the antenna as the ground plane and its cylindrical waveguide accounts for almost $2 / 3$ of the initial design antenna height. While reducing the antenna dimensions, it is important to keep acceptable electrical performance especially in terms of input matching and rear radiation level.

Parametric studies on the impact of ground plane and its loading structure were conducted and reported in [4]. It leads to an original topology of ground plane loaded with truncated conical cut-off open-ended waveguide (See Fig. 6(a)). The pyramidal antenna loaded with this conical waveguide presents input matching performance equivalent to that obtained with a ground plane having a cylindrical waveguide while having rear radiation performance equivalent to the nonperforated ground plane. Actually, this new configuration allows minimizing the rear radiation level and having a sufficient input matching with a height reduction of $57 \%$ compared to the antenna loaded with a cylindrical waveguide. Only the axial ratio is slightly degraded by the use of truncated waveguide instead of the cylindrical one, but it remains good enough for most GNSS applications.

Another solution found to further reduce the height of the antenna is to suppress the cylindrical cut-off waveguide. It is evident that if we keep the configuration with only a centered hole reaching to the feeding points of the radiating elements, rear radiation level is going to increase significantly. Consequently, the authors investigated the possibility to replace the large centered hole by several smaller holes in the ground plane [3]. Since these smaller holes are well under cutoff conditions at all the antenna operating frequencies the adjunction of waveguides can be avoided. As a matter of fact, considering the finite thickness of the ground plane, each hole in the ground plane can be seen as small waveguide with a length equal to the thickness of the ground plane. One can possibly play with this thickness to refine the performance of the antenna.

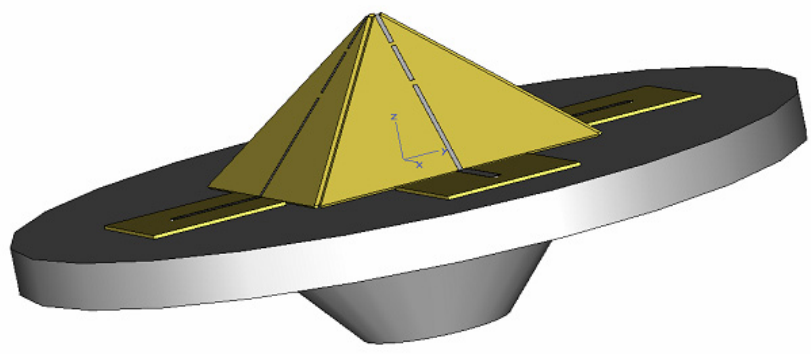

(a)

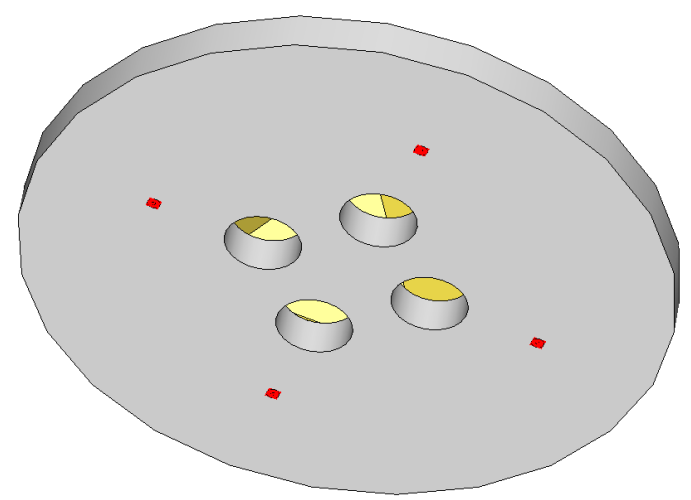

(b)

Fig. 6: Ground plane configurations [4]: (a) Ground plane loaded with truncated conical cut-off open-ended waveguide; (b) Ground plane with multiple holes.

Fig. 6(b) gives an example with four circular holes perforated in the ground plane, one hole per radiating element. The number and the shape of these holes have a significant impact on the performance of the antenna. The influence of these parameters was studied. It was found that circular holes generally give better antenna performance than rectangular holes in terms of radiation and input matching. It was also found that the bigger the holes radius the better the input matching, but the higher the rear radiation level. Thus, this second ground plane configuration was found to be an intermediate between previous configurations and the antenna with a non-perforated ground plane. However, since the input matching improvement is not as significant as with the other configurations, this solution is to be used only when strong constraints apply to the antenna dimensions. 
These two new configurations of ground plane keep obviously all the advantages of the initial solution, namely the simple design and the flexibility features on the definition of the frequency plan as well as the choice of polarization.

\section{INTERLEAVED MULTI-BAND PYRAMIDAL ANTENNA}

As previously described, the multi-band behavior of the pyramidal antenna is achieved using trap-loads that enable to adapt the length of the radiating element to the multiple operating frequencies. These trap-loads limit in some way the available bandwidth at higher resonant frequencies. Also, if two different polarizations are required for the two combined applications (radio navigation requires right hand circular polarization, but telemetry may require right- or left-hand circular polarization depending on the mission), some difficulties in the design may appear at feeding network level. To overcome these limitations, it is interesting to separate the applications by interleaving the antennas [5]. A $45^{\circ}$ interleaved pyramidal antenna combining radio navigation and telemetry applications is depicted in Fig. 7. Interestingly, this improvement of the multi-band antenna does not affect the overall antenna size and the two applications are naturally separated making it easier to design the respective feeding networks. This new design enables also to overcome bandwidth limitation problems as only one trap-load is now needed per radiating element on the radio navigation antenna. Coupling effects appear to have negligible impact on both input matching and radiation patterns. Finally, we may also mention that this interleaved pyramidal antennas design gives further optimization parameters to better fit the antenna performance to the specifications. For instance, one may set a different inclination angle for the two antennas.

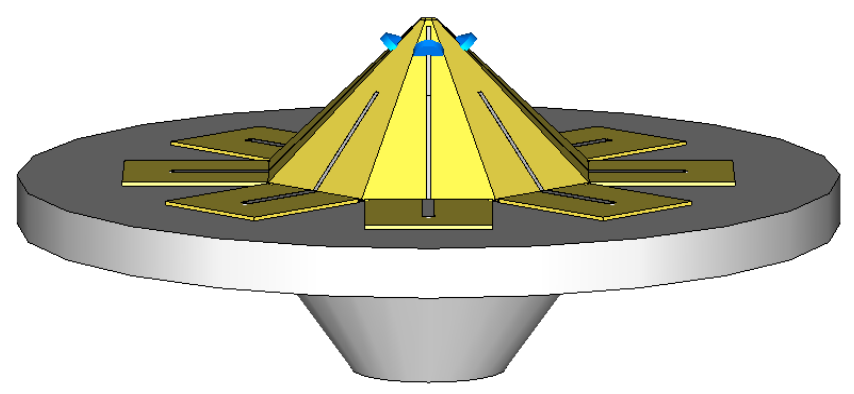

Fig. 7: $45^{\circ}$-Interleaved multiband pyramidal antenna loaded with truncated conical waveguide [5]

\section{CONCLUSION}

In this paper, an overview and the latest improvements on the design of a recently published pyramidal multiband antenna were given. By the simple structure feature of this antenna, various possible adjustments (inclination angles, geometry of the metallic radiating elements and ground plane, trap-loads/switches) contribute to a multi-application use. After describing the initial pyramidal structure, parametric study were conducted on the impact of the ground plane and its loading structure. These analyses led to a new topology of ground plane that reduces the overall height of the antenna by
$57 \%$ without much affecting the electrical performance of the antenna. A solution with flat ground plane was also investigated for applications requiring further compactness. Finally, in order to simplify the multiband feeding network required by the antenna, a novel interleaved pyramidal antenna were proposed and described.

\section{ACKNOWLEDGEMENT}

The activities reported in this paper were supported by the French Space Agency (CNES).

The authors would like to thank C. Mangenot and B. Palacin for their contributions.

\section{REFERENCES}

[1] S. Hebib, H. Aubert, O. Pascal, N. Fonseca, L. Ries, J.-M. E. Lopez, "Multiband pyramidal antenna loaded by a cutoff open-ended waveguide," IEEE Transactions on Antennas and Propagation, vol. 57, no. 1, pp. 266-270, Jan. 2009.

[2] S. Hebib, "Nouvelle Topologie d'Antennes Multi-bandes pour Applications Spatiales", PhD Thesis, Université de Toulouse, France.

[3] S. Hebib, H. Aubert, O. Pascal, N. Fonseca, L. Ries, "Antenna having oblique radiating elements", International patent No WO2008125662, 23 October 2008.

[4] B. Palacin, N. Fonseca, S. Hebib, H. Aubert, "Impact of the ground plane topology on the performance of a pyramidal multiband quadrielement antenna," accepted for presentation at the 4th European Conference on Antennas and Propagation (EuCAP), April 12-16, 2010, Barcelona, Spain.

[5] N. Fonseca, C. Mangenot, S. Hebib, H. Aubert, O. Pascal, "Interleaved multi-Band pyramidal antennas combining radio navigation and telemetry satellite applications," 2009 IEEE AP-S Int. Symp., June 1-5, Charleston, USA.

[6] S. Hebib, H. Aubert, O. Pascal, N. Fonseca, L. Ries, J.-M. E. Lopez, "Sierpinski pyramidal antenna loaded with a cutoff open-ended waveguide," IEEE Antennas and Wireless propagation letters, vol. 8, pp. 352-355, 2009.

[7] S. Hebib, H. Aubert, O. Pascal, N. Fonseca, L. Ries, J.-M. Lopez, "Reconfigurable pyramidal antenna loaded by a cut-off waveguideapplication to ARNS/RNSS services," in Proceedings of the 3rd European Conference on Antennas and Propagation (EuCAP), pp. 1882-1885, March 23-27, 2009, Berlin, Germany. 